\title{
Higher-order aberrations after wavefront-optimized photorefractive keratectomy and laser in situ keratomileusis
}

\author{
J. Bradley Randleman, MD, Claudia E. Perez-Straziota, MD, Michelle H. Hu, Alfred J. White, \\ Evan S. Loft, MD, and R. Doyle Stulting, MD, PhD \\ Emory University School of Medicine (Randleman, Hu, White, Stulting) and private practices \\ (Randleman, Perez-Straziota, Loft, Stulting), Atlanta, Georgia, USA.
}

\begin{abstract}
PURPOSE-To analyze the changes in higher-order aberrations (HOAs) that occur after wavefront-optimized photorefractive keratectomy (PRK) and laser in situ keratomileusis (LASIK).

SETTING-Private practice, Atlanta, Georgia, USA.

METHODS-This retrospective analysis comprised eyes that had PRK or LASIK from June 2004 through October 2005. Postoperative outcome measures included 3-month uncorrected visual acuity (UCVA), best spectacle-corrected visual acuity (BSCVA), manifest refraction spherical equivalent (MRSE), changes in the root mean square (RMS) and grouped coefficient HOAs (microns) measured with a corneal analyzer, and subjective assessment of visual aberrations.
\end{abstract}

RESULTS-One hundred consecutive eyes of 54 patients had PRK, and 100 contemporaneous consecutive eyes of 71 patients had LASIK. The PRK and LASIK populations were similar in general demographics, preoperative HOAs, and postoperative UCVA and BSCVA. The mean MRSE was slightly hyperopic after PRK (mean +0.11 diopters [D]) and slightly myopic after LASIK (mean -0.19 D) ( $P<.0001)$. There were no statistically significant changes in RMS or grouped coefficient HOA values after PRK or LASIK, nor were there significant differences in postoperative RMS or grouped coefficient HOA values between PRK and LASIK. One percent of PRK and LASIK patients reported a subjective increase in postoperative visual aberrations; 5\% reported a subjective improvement postoperatively.

CONCLUSIONS-Wavefront-optimized excimer laser surgery did not induce significant HOAs after PRK or LASIK. The 2 techniques were equally efficacious and had equivalent postoperative HOA profiles.

\begin{abstract}
Excimer laser corneal refractive surgery for the correction of refractive error is safe and effective, and most patients have excellent uncorrected (UCVA) and best spectaclecorrected visual acuity (BSCVA) after photorefractive keratectomy (PRK) or laser in situ keratomileusis (LASIK). ${ }^{1,2}$ However, some patients report unwanted postoperative visual symptoms including glare, halos, starbursts, and other visual phenomena. ${ }^{3,4}$
\end{abstract}

\footnotetext{
(C) 2008 American Society of Cataract and Refractive Surgery and European Society of Cataract and Refractive Surgeons. Published by Elsevier Inc. All rights reserved.

Corresponding author: J. Bradley Randleman, MD, 1365 B Clifton Road NE, Suite 4500, Atlanta, Georgia 30322. jrandle@emory.edu.

Publisher's Disclaimer: This is a PDF file of an unedited manuscript that has been accepted for publication. As a service to our customers we are providing this early version of the manuscript. The manuscript will undergo copyediting, typesetting, and review of the resulting proof before it is published in its final citable form. Please note that during the production process errors may be discovered which could affect the content, and all legal disclaimers that apply to the journal pertain.

No author has a financial or proprietary interest in any material or method mentioned.
} 
Conventional LASIK has been shown to induce higher-order aberrations (HOAs) $)^{5-11}$ including increased root-mean-square (RMS) error, ${ }^{8}$ increased total HOAs, ${ }^{5,9}$ coma, ${ }^{5-7,9}$ and spherical aberrations. ${ }^{5-9}$ Chalita $^{6,7}$ and Melamud ${ }^{10}$ found that complaints of monocular diplopia were correlated with induced coma and complaints of starburst and glare were correlated with induced spherical aberration. Yamane et al. ${ }^{9}$ found that reduced contrast sensitivity function postoperatively was correlated with induced total HOA, coma, and spherical aberration. Sharma et al. ${ }^{11}$ found that RMS values more than twice normal postoperative values significantly increased the risk for subjective complaints. Advances in laser ablation profiles, including increased ablation zone diameters and wavefront-guided and wavefront-optimized platforms, have sought to minimize the induction of glare, halos, and other postoperative visual aberrations.

This study was designed to analyze changes in HOAs that occur after wavefront-optimized PRK and LASIK.

\section{PATIENTS AND METHODS}

A retrospective analysis of eyes that had PRK or LASIK at Emory Vision, Atlanta, Georgia, from June 2004 through October 2005 was performed. Emory University Investigative Review Board approval was granted for this study. Patients were excluded from analysis if they had previous ocular surgery, were not targeted for emmetropia, or did not have sufficient preoperative or postoperative information.

Significantly more patients had LASIK than had PRK during the study period; therefore, all consecutive PRK eyes with the necessary data were included and a consecutive contemporaneous population of preoperative refraction-matched LASIK eyes was used for comparison.

All cases were performed with the WaveLight Allegretto Wave excimer laser (WaveLight AG). The laser incorporates wavefront-optimized technology (U.S. Food and Drug Administration Premarket Approval Application Number P030008, October 2003). All LASIK flaps were created with the Amadeus I microkeratome (Advanced Medical Optics) using a $140.0 \mu \mathrm{m}$ plate with Surgical Instrument Systems Surepass blades (Advanced Medical Optics). For PRK cases, epithelial removal was performed in 1 of 2 ways based on surgeon preference: (1) $20 \%$ ethanol in a well or on a $20 \%$ ethanol-soaked corneal light shield for 30 seconds followed by mechanical removal or (2) use of the Amoils brush (Innovative Excimer Solutions). In all PRK cases, mitomycin-C 0.02\% was applied to the stromal bed after laser ablation for 30 seconds to 2 minutes based on surgeon preference. No nomogram adjustments were made for PRK or LASIK treatments.

Preoperative information recorded included patient age and sex, date of surgery, surgeon, manifest refraction spherical equivalent (MRSE), BSCVA, and HOAs.

Higher-order aberrations were measured with the OPD-Scan ARK-10000 corneal analyzer (Nidek Technologies) preoperatively and at the 3-month postoperative visit. Grouped RMS and grouped coefficient Zernike values were analyzed. The RMS values included total HOA, coma, trefoil, tetrafoil, and spherical aberration. Grouped coefficient values included coma (terms 7 and 8), trefoil (terms 6 and 9), tetrafoil (term 10), and spherical aberration (term 12). Wavefront analysis was performed across a naturally dilated pupil with a diameter of $6.0 \mathrm{~mm}$ or larger and the wavefront analysis, over this central $6.0 \mathrm{~mm}$ zone. Subjective visual aberration analysis was also performed, with patients reporting problems with halos, night driving, ghosting, or double images on a 0 to 4 scale preoperatively and 3 months postoperatively. 
Outcome measures included UCVA, BSCVA, MRSE, RMS and grouped coefficient HOAs, and subjective reports of aberrations 3 months postoperatively.

Statistical analyses were performed using the Student $t$ test and chi-square analysis. To compensate for approximately 50 separate comparisons, $P$ values less than 0.001 were considered significant (using the Bonferroni method to adjust for multiple comparisons).

\section{RESULTS}

One hundred consecutive eyes of 54 patients had PRK, and 100 consecutive contemporaneous eyes of 71 patients had LASIK. The PRK and LASIK populations were similar in general demographics (Table 1) and preoperative HOAs (Table 2).

Postoperative UCVA and BSCVA were also similar between groups (Table 1); however, the mean MRSE was slightly hyperopic after PRK and slightly myopic after LASIK. This difference was statistically significant $(P<.0001)$.

There were no significant changes in RMS or grouped coefficient HOA values after PRK (Figure 1) or LASIK (Figure 2) (both $P>.001$ ). There were no significant differences in RMS or grouped coefficient postoperative HOA values between PRK and LASIK ( $P>.001)$ (Figure 3). Most patients reported no change in subjective visual aberrations after PRK or LASIK; $1 \%$ noted subjective worsening and 5\% noted subjective improvements postoperatively (Figure 4). All eyes with subjective worsening had a postoperative UCVA of $20 / 20$ or better with plano refractions.

\section{DISCUSSION}

In this study, excimer laser surgery using a wavefront-optimized platform did not induce significant HOAs after PRK or LASIK and postoperative HOA profiles were equivalent between the 2 surgical techniques. Furthermore, only $1 \%$ of all patients reported a subjective increase in subjective visual aberrations postoperatively while 5\% reported postoperative subjective improvement.

Although several techniques to measure and quantify HOAs are available; the technique that most effectively models the human cornea remains undetermined. ${ }^{12-14}$ The OPD-Scan ARK-10000 aberrometer combines Placido disk keratography and wavefront aberrometry based on dynamic skiascopy. The aberrometer calculates the wavefront error using timebased aberrometry as opposed to position-based aberrometry. The fundus reflex from the unit's scanning light source creates a time difference signal on 1440 points of the corneal plane in the $2.0 \mathrm{~mm}$ and $6.0 \mathrm{~mm}$ zones. This signal is converted into a wavefront ${ }^{15-17}$ and then compared with measurements in an emmetropic eye as a point of reference; a colorscaled graphic representation of these differences is created. There has been some question as to the repeatability of HOA measurements with the OPD-Scan ${ }^{18}$; however, we do not believe that this significantly influenced the results in the population in our study; that is, the lack of significant HOA in either group and the lack of significant differences between groups.

Peripheral ablation profiles differ between conventional and wavefront-optimized laser platforms and may be related to postoperative HOA, subjective visual aberrations, or both. The angle of incidence between the laser beam and the surface of the cornea differs depending on its location. At the center of the cornea, the angle is approximately 90 degrees; it decreases progressively as the point of incidence moves toward the limbus. This phenomenon has been shown to result in a $10 \%$ to $15 \%$ reduction in the amount of ablated tissue in the periphery during standard treatments with a $6.5 \mathrm{~mm}$ optical zone, ${ }^{19}$ inducing 
positive spherical aberrations and accounting, at least in part, for optical aberrations created by conventional LASIK treatments. ${ }^{5-11,19-22}$

The WaveLight Allegretto Wave is a flying-spot laser with a $0.95 \mathrm{~mm}$ gaussian beam, a 200 $\mathrm{Hz}$ repetition rate, and a tracker with a $6.0 \mathrm{~ms}$ response time specifically designed to minimize the induction of high HOAs after LASIK. Optimized treatments are based on manifest refraction, as opposed to custom or aberrometer-based treatments. They do not differ from standard treatments in central ablation depth; however, optimized treatments increase the laser energy delivered to the peripheral cornea in an attempt to preserve the cornea's original asphericity. ${ }^{19}$ Wavefront-guided ablations with the this laser may further improve postoperative HOA profiles compared with wavefront-optimized profiles, but only in selected patients. ${ }^{23,24}$

In addition to the laser platform, several other factors are reported to influence postoperative HOAs; these include the type of surgery (surface ablation versus LASIK), ${ }^{5,25}$ amount of correction, 5,22 ablation zone, ${ }^{26}$ LASIK flap creation, ${ }^{27-29}$ method of LASIK flap creation (mechanical microkeratome versus femtosecond laser), ${ }^{30,31}$ variable ablation depths per laser pulse, ${ }^{32}$ and variable corneal biologic responses to the laser. ${ }^{32}$ However, there is discrepancy in the literature regarding the relative contribution of these parameters. We did not measure HOAs after creation of a flap without laser ablation. However, we found no difference in the amount of HOA induced by LASIK and that induced by PRK. This suggests that the flap itself does not contribute significantly to postoperative HOAs. It is possible, although unlikely, that postoperative HOA profiles could change after 3 months; studies with longer comparative follow-up would be needed to evaluate this.

In summary, wavefront-optimized excimer laser ablations did not induce significant objective or subjective HOAs after LASIK or PRK. Both procedures were equally efficacious.

\section{Acknowledgments}

Supported in part by Research to Prevent Blindness, Inc., New York, New York, and National Institutes of Health Core Grant P30 EYO6360, Bethesda, Maryland, USA.

\section{REFERENCES}

1. American Academy of Ophthalmology. Excimer laser photorefractive keratectomy (PRK) for myopia and astigmatism. Ophthalmic procedure preliminary assessment. Ophthalmology. 1999; 106:422-437. [PubMed: 9951501]

2. Sugar A, Rapuano CJ, Culbertson WW, Huang D, Varley GA, Agapitos PJ, de Luise VP, Koch DD. Laser in situ keratomileusis for myopia and astigmatism: safety and efficacy. (Ophthalmic Technology Assessment) A report by the American Academy of Ophthalmology. Ophthalmology. 2002; 109:175-187. [PubMed: 11772601]

3. Jabbur NS, Sakatani K, O'Brien TP. Survey of complications and recommendations for management in dissatisfied patients seeking a consultation after refractive surgery. J Cataract Refract Surg. 2004; 30:1867-1874. [PubMed: 15342048]

4. Bailey MD, Mitchell GL, Dhaliwal DK, Boxer Wachler BS, Zadnik K. Patient satisfaction and visual symptoms after laser in situ keratomileusis. Ophthalmology. 2003; 110:1371-1378. [PubMed: 12867394]

5. Buzzonetti L, Iarossi G, Valente P, Volpi M, Petrocelli G, Scullica L. Comparison of wavefront aberration changes in the anterior corneal surface after laser-assisted subepithelial keratectomy and laser in situ keratomileusis: preliminary study. J Cataract Refract Surg. 2004; 30:1929-1933. [PubMed: 15342057] 
6. Chalita MR, Chavala S, Xu M, Krueger RR. Wavefront analysis in post-LASIK eyes and its correlation with visual symptoms, refraction, and topography. Ophthalmology. 2004; 111:447-453. [PubMed: 15019317]

7. Chalita MR, Xu M, Krueger RR. Correlation of aberrations with visual symptoms using wavefront analysis in eyes after laser in situ keratomileusis. J Refract Surg. 2003; 19:S682-S686. [PubMed: 14640435]

8. Moreno-Barriuso E, Merayo Lloves J, Marcos S, Navarro R, Llorente L, Barbero S. Ocular aberrations before and after myopic corneal refractive surgery: LASIK-induced changes measured with laser ray tracing. Invest Ophthalmol Vis Sci. 2001; 42:1396-1403. Available at: http:// www.iovs.org/cgi/reprint/42/6/1396.pdf. [PubMed: 11328757]

9. Yamane N, Miyata K, Samejima T, Hiraoka T, Kiuchi T, Okamoto F, Hirohara Y, Mihashi T, Oshika T. Ocular higher-order aberrations and contrast sensitivity after conventional laser in situ keratomileusis. Invest Ophthalmol Vis Sci. 2004; 45:3986-3990. Available at: http://www.iovs.org/ cgi/reprint/45/11/3986. [PubMed: 15505046]

10. Melamud A, Chalita MR, Krueger RR, Lee MS. Comatic aberration as a cause of monocular diplopia. J Cataract Refract Surg. 2006; 32:529-532. [PubMed: 16631071]

11. Sharma M, Boxer Wachler BS, Chan CCK. Higher order aberrations and relative risk of symptoms after LASIK. J Refract Surg. 2007; 23:252-256. [PubMed: 17385290]

12. Smolek MK, Klyce SD. Goodness-of-prediction of Zernike polynomial fitting to corneal surfaces. J Cataract Refract Surg. 2005; 31:2350-2355. [PubMed: 16473230]

13. Ou JI, Manche EE. Zernike versus Fourier treatment tables for myopic patients having CustomVue wavefront laser in situ keratomileusis with the S4 excimer laser. J Cataract Refract Surg. 2007; 33:654-657. [PubMed: 17397739]

14. Wang L, Chernyak D, Yeh D, Koch DD. Fitting behaviors of Fourier transform and Zernike polynomials. J Cataract Refract Surg. 2007; 33:999-1004. [PubMed: 17531693]

15. Yeung IYL, Mantry S, Cunliffe IA, Benson MT, Shah S. Correlation of Nidek OPD-Scan objective refraction with subjective refraction. J Refract Surg. 2004; 20:S734-S736. [PubMed: 15521279]

16. Klyce SD, Karon MD, Smolek MK. Advantages and disadvantages of the Zernike expansion for representing wave aberration of the normal and aberrated eye. J Refract Surg. 2004; 20:S537S541. [PubMed: 15523972]

17. Buscemi P. Clinical applications of the OPD-Scan wavefront aberrometer/corneal topographer. J Refract Surg. 2002; 18:S385-S388. [PubMed: 12046890]

18. Zadok D, Levy Y, Segal O, Barkana Y, Morad Y, Avni I. Ocular higher-order aberrations in myopia and skiascopic wavefront repeatability. J Cataract Refract Surg. 2005; 31:1128-1132. [PubMed: 16039485]

19. Mrochen M, Donitzky C, Wüllner C, Löffler J. Wavefront-optimized ablation profiles: theoretical background. J Cataract Refract Surg. 2004; 30:775-785. [PubMed: 15093638]

20. Oshika T, Klyce SD, Applegate RA, Howland HC, El Danasoury MA. Comparison of corneal wavefront aberrations after photorefractive keratectomy and laser in situ keratomileusis. Am J Ophthalmol. 1999; 127:1-7. [PubMed: 9932992]

21. Lee D-H, Oh JR, Reinstein DZ. Conservation of corneal tissue with wavefront-guided laser in situ keratomileusis. J Cataract Refract Surg. 2005; 31:1153-1158. [PubMed: 16039489]

22. Pesudovs K. Wavefront aberration outcomes of LASIK for high myopia and high hyperopia. J Refract Surg. 2005; 21:S508-S512. [PubMed: 16209452]

23. Kaiserman I, Hazarbassanov R, Varssano D, Grinbaum A. Contrast sensitivity after wave frontguided LASIK. Ophthalmology. 2004; 111:454-457. [PubMed: 15019318]

24. Padmanabhan P, Mrochen M, Basuthkar S, Viswanathan D, Joseph R. Wavefront-guided versus wavefront-optimized laser in situ keratomileusis: contralateral comparative study. J Cataract Refract Surg. 2008; 34:389-397. [PubMed: 18299062]

25. Chung S-H, Lee IS, Lee YG, Lee HK, Kim EK, Yoon G, Seo KY. Comparison of higher-order aberrations after wavefront-guided laser in situ keratomileusis and laser-assisted subepithelial keratectomy. J Cataract Refract Surg. 2006; 32:779-784. [PubMed: 16765794]

26. Mok KH, Lee VW-H. Effect of optical zone ablation diameter on LASIK-induced higher order optical aberrations. J Refract Surg. 2005; 21:141-143. [PubMed: 15796217] 
27. Waheed S, Chalita MR, Xu M, Krueger RR. Flap-induced and laser-induced ocular aberrations in a two-step LASIK procedure. J Refract Surg. 2005; 21:346-352. [PubMed: 16128331]

28. Zadok D, Carrillo C, Missiroli F, Litwak S, Robledo N, Chayet AS. The effect of corneal flap on optical aberrations. Am J Ophthalmol. 2004; 138:190-193. [PubMed: 15289125]

29. Pallikaris IG, Kymionis GD, Panagopoulou SI, Siganos CS, Theodorakis MA, Pallikaris AI. Induced optical aberrations following formation of a laser in situ keratomileusis flap. J Cataract Refract Surg. 2002; 28:1737-1741. [PubMed: 12388021]

30. Buzzonetti L, Petrocelli G, Valente P, Tamburrelli C, Mosca L, Laborante A, Balestrazzi E. Comparison of corneal aberration changes after laser in situ keratomileusis performed with mechanical microkeratome and IntraLase femtosecond laser: 1-year follow-up. Cornea. 2008; 27:174-179. [PubMed: 18216572]

31. Medeiros FW, Stapleton WM, Hammel J, Krueger RR, Netto MV, Wilson SE. Wavefront analysis comparison of LASIK outcomes with the femtosecond laser and mechanical microkeratomes. J Refract Surg. 2007; 23:880-887. [PubMed: 18041240]

32. Yoon G, MacRae S, Williams DR, Cox IG. Causes of spherical aberration induced by laser refractive surgery. J Cataract Refract Surg. 2005; 31:127-135. [PubMed: 15721705]

\section{Biography}

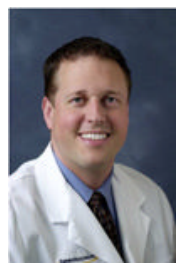




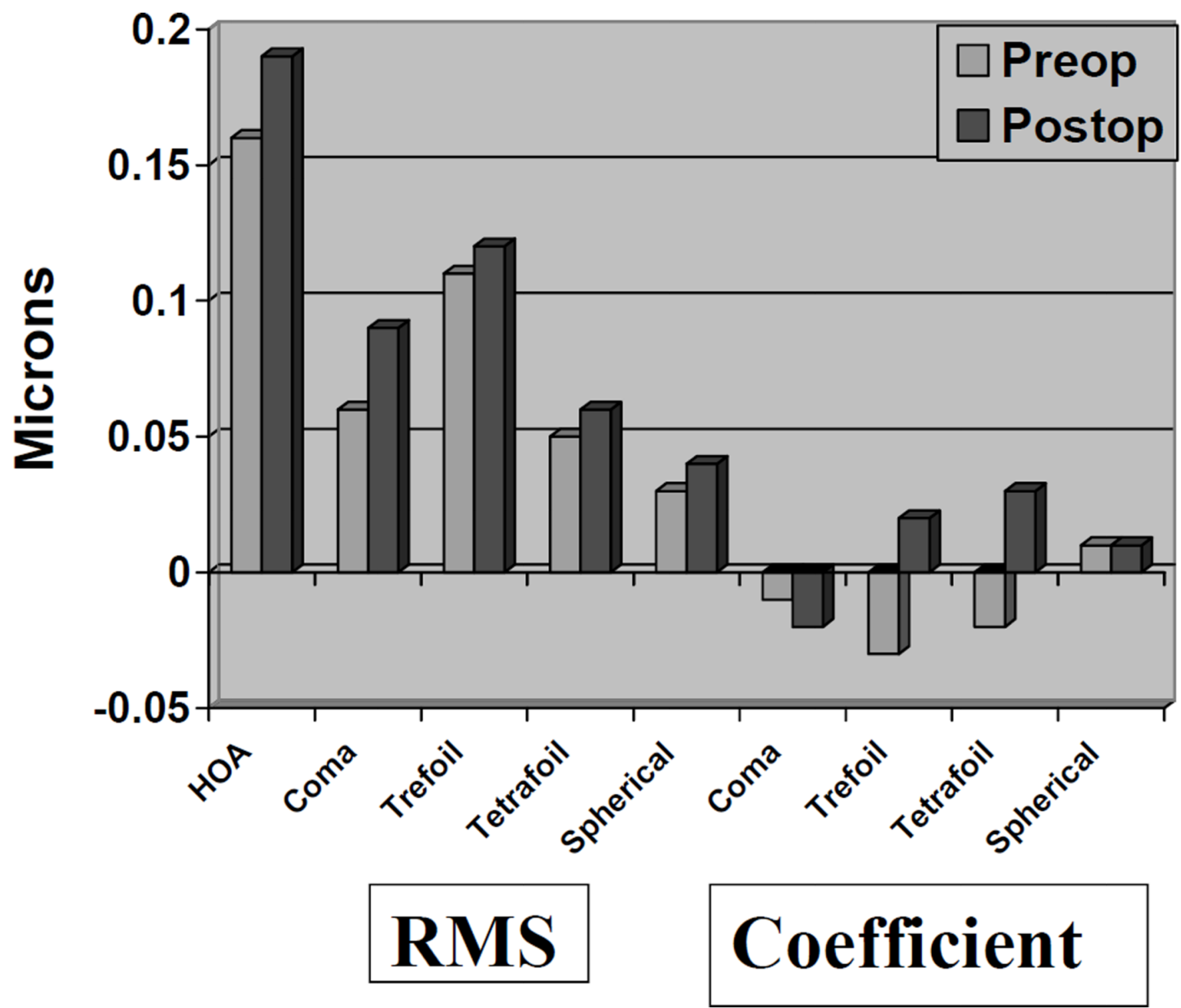

Figure 1.

Higher-order aberrations after PRK (RMS = root mean square). 


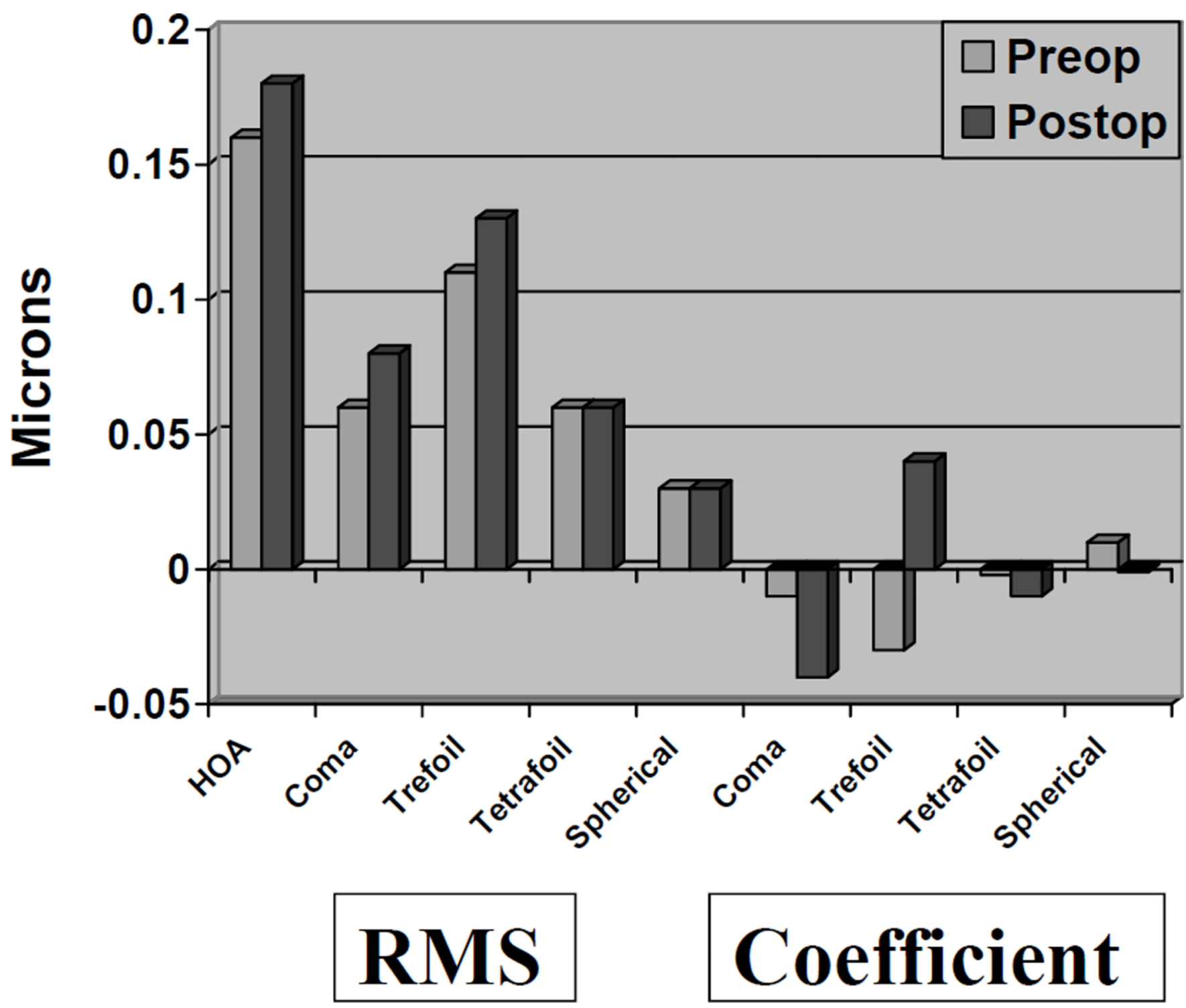

Figure 2.

High order aberrations after LASIK (RMS = root mean square). 


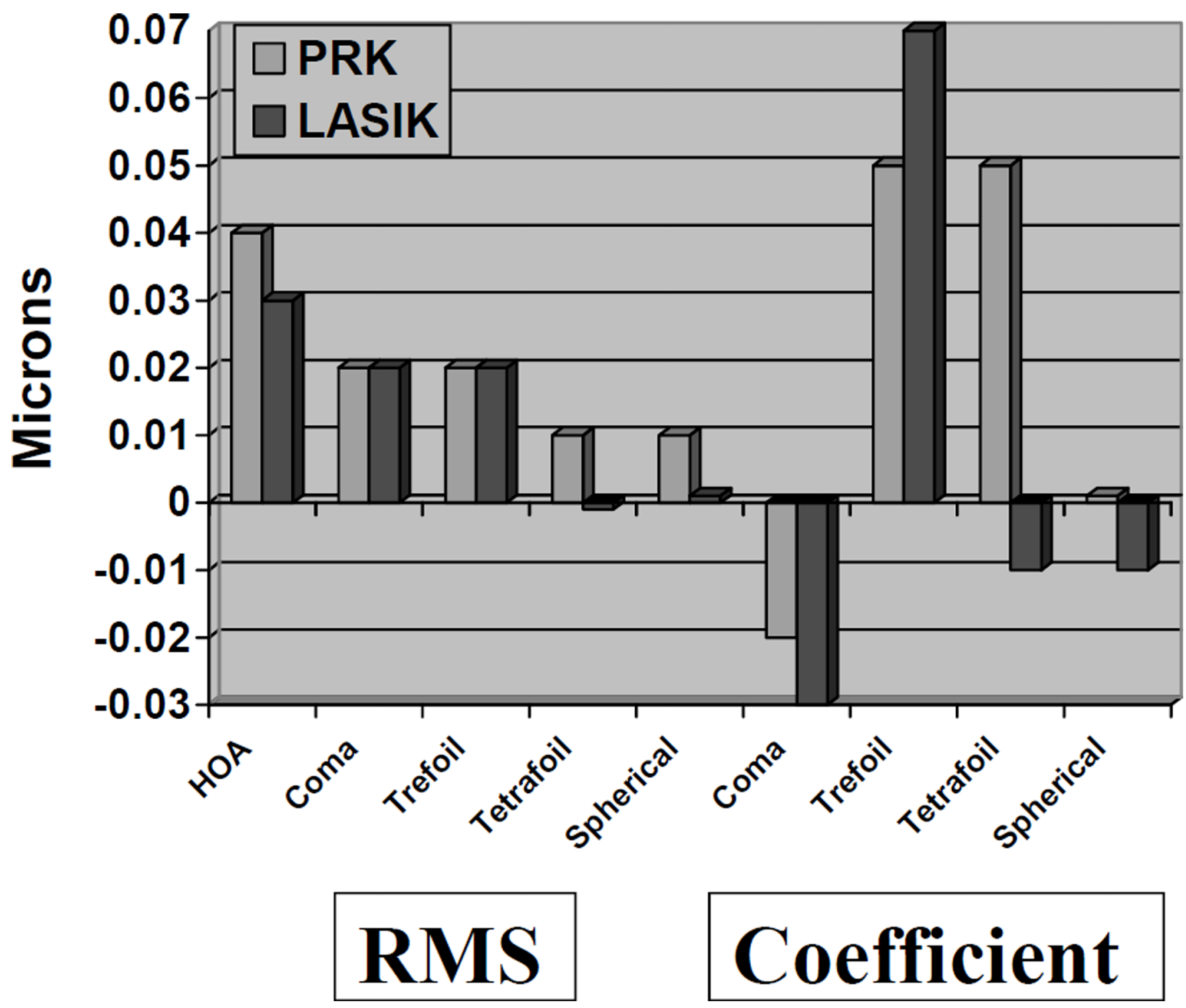

Figure 3.

Comparison of HOA changes after PRK and LASIK (LASIK = laser in situ keratomileusis; PRK = photorefractive keratectomy; RMS = root mean square). 


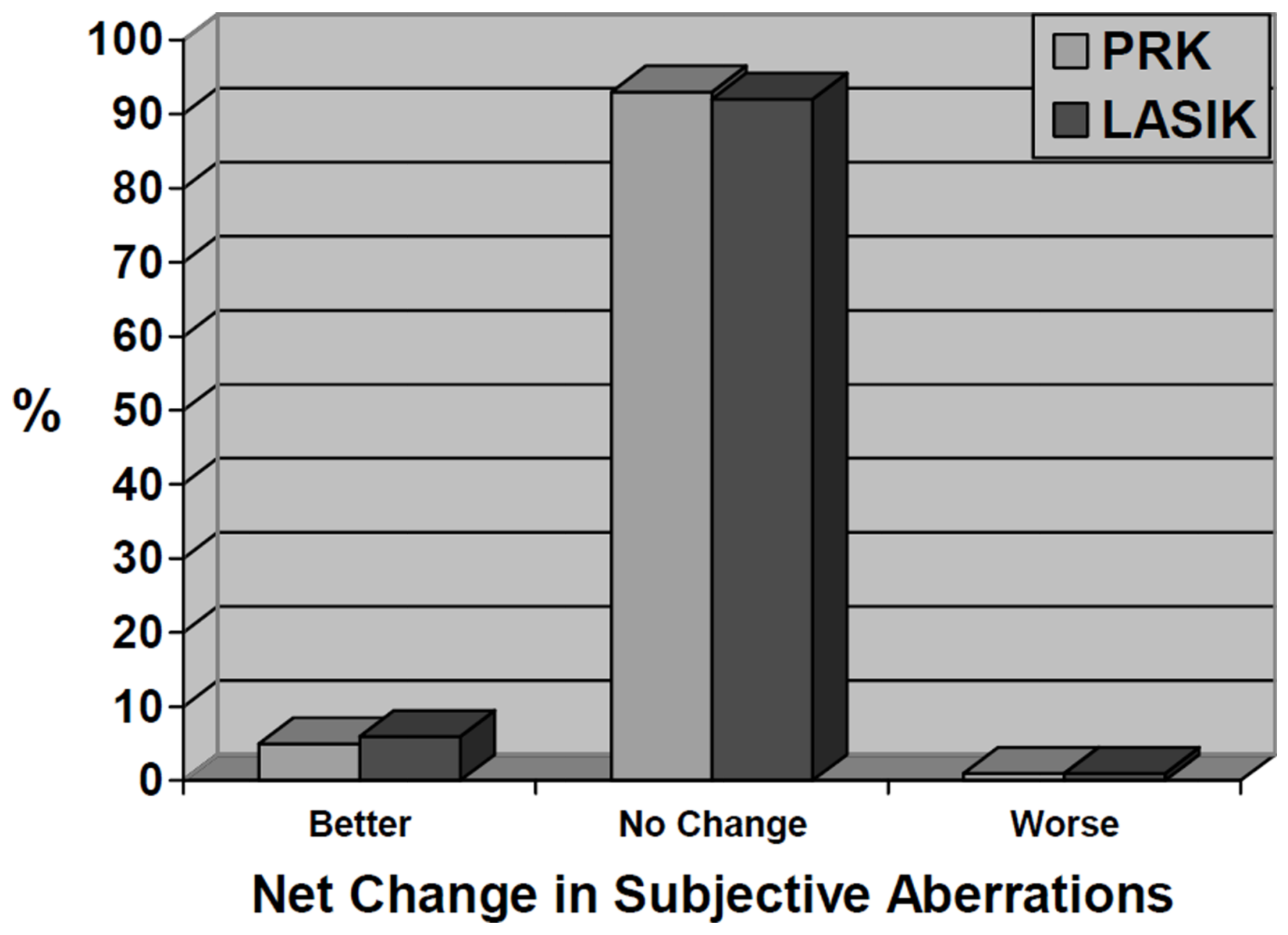

Figure 4.

Comparison of subjective visual aberration changes after PRK and LASIK (LASIK = laser in situ keratomileusis; PRK = photorefractive keratectomy). Wavefront-optimized excimer laser PRK or LASIK did not induce higher-order aberrations. Both procedures were equally efficacious. 


\section{Table 1}

Patient demographics.

\begin{tabular}{lccc}
\hline Demographic & PRK (n= 100) & LASIK (n= 100) & $\boldsymbol{P}$ Value \\
Sex (\% male) & 42 & 55 & .09 \\
Age (y) & 36.2 & 37.9 & .2 \\
Mean & 18 to 59 & 22 to 60 & \\
Range & & & .9 \\
Preoperative MRSE (D) & -4.97 & -4.98 & \\
Mean & -0.75 to -9.00 & -0.75 to -9.00 & \\
Range & & & .03 \\
Preoperative BSCVA (20/x) & 19.3 & 18.5 & \\
Mean & 15 to 25 & 15 to 25 & \\
Range & & & .2 \\
Postoperative outcomes & & & \\
3-month UCVA (20/x) & 22.3 & 24.7 & \\
Mean & 15 to 60 & 15 to 70 & \\
Range & & & \\
3-month BSCVA (20/x) & 18.3 & 17.8 & \\
Mean & 10 to 25 & 15 to 25 & \\
Range & & & \\
3-month MRSE (D) & +0.11 & -0.19 & \\
Mean & -1.00 to +1.00 & +0.75 to -0.875 & \\
Range & & & \\
\hline
\end{tabular}

BSCVA = best spectacle-corrected visual acuity; LASIK = laser in situ keratomileusis; MRSE = manifest refraction spherical equivalent; PRK = photorefractive keratectomy; UCVA = uncorrected visual acuity 
Table 2

Preoperative HOAs.

\begin{tabular}{|c|c|c|c|}
\hline Higher-Order Aberration & PRK $(n=100)$ & $\operatorname{LASIK}(\mathbf{n}=100)$ & $P$ Value \\
\hline \multicolumn{4}{|l|}{ Root mean square $(\mu \mathrm{m})$} \\
\hline Total HOA & & & .9 \\
\hline Mean \pm SD & $0.16 \pm 0.12$ & $0.16 \pm 0.15$ & \\
\hline Range & 0.05 to 0.95 & 0.05 to 0.90 & \\
\hline Coma & & & .5 \\
\hline Mean \pm SD & $0.06 \pm 0.04$ & $0.05 \pm 0.03$ & \\
\hline Range & 0.01 to 0.38 & 0.01 to 0.13 & \\
\hline Trefoil & & & .8 \\
\hline Mean \pm SD & $0.11 \pm 0.07$ & $0.10 \pm 0.06$ & \\
\hline Range & 0.02 to 0.44 & 0.01 to 0.34 & \\
\hline Tetrafoil & & & .5 \\
\hline Mean \pm SD & $0.05 \pm 0.10$ & $0.06 \pm 0.15$ & \\
\hline Range & 0.00 to 0.86 & 0.00 to 0.82 & \\
\hline Spherical aberration & & & .7 \\
\hline Mean \pm SD & $0.03 \pm 0.03$ & $0.03 \pm 0.04$ & \\
\hline Range & 0.00 to 0.16 & 0.00 to 0.32 & \\
\hline \multicolumn{4}{|l|}{ Coefficient $(\mu \mathrm{m})$} \\
\hline Coma & & & 6 \\
\hline Mean \pm SD & $-0.01 \pm 0.05$ & $-0.01 \pm 0.06$ & \\
\hline Range & -0.12 to 0.16 & -0.21 to 0.16 & \\
\hline Trefoil & & & .9 \\
\hline Mean \pm SD & $-0.03 \pm 0.16$ & $-0.03 \pm 0.12$ & \\
\hline Range & -0.97 to 0.29 & -0.38 to 0.40 & \\
\hline Tetrafoil & & & .5 \\
\hline Mean \pm SD & $-0.01 \pm 0.18$ & $-0.002 \pm 0.11$ & \\
\hline Range & -0.61 to 0.17 & -0.43 to 0.66 & \\
\hline Spherical aberration & & & .6 \\
\hline Mean \pm SD & $0.01 \pm 0.04$ & $0.01 \pm 0.05$ & \\
\hline Range & -0.16 to 0.10 & -0.34 to 0.06 & \\
\hline
\end{tabular}

Coefficient $=$ grouped higher-order aberration coefficient values; $\mathrm{HOA}=$ higher-order aberrations; LASIK $=$ laser in situ keratomileusis; $\mathrm{PRK}=$ photorefractive keratectomy; RMS = root-mean-square values 